\title{
Fabrication of Transparent Conductive Zinc Oxide Co-Doped with Fluorine and Zirconium Thin Solid Films by Ultrasonic Chemical Pyrolysis: Effects of Precursor Solution Aging and Substrate Temperature
}

\author{
Luis Castañeda \\ Escuela Superior de Ingeniería Mecánica y Eléctrica Unidad Ticomán, Instituto Politécnico Nacional, 07340 Mexico, DF, Mexico \\ Correspondence should be addressed to Luis Castañeda; luiscas@cablevision.net.mx \\ Received 1 April 2013; Revised 31 May 2013; Accepted 9 June 2013 \\ Academic Editor: Mamoru Furuta \\ Copyright (C) 2013 Luis Castañeda. This is an open access article distributed under the Creative Commons Attribution License, \\ which permits unrestricted use, distribution, and reproduction in any medium, provided the original work is properly cited. \\ Highly transparent, conducting zinc oxide $[\mathrm{ZnO}]$ thin films co-doped with fluorine and zirconium have been deposited on glass \\ substrates by the ultrasonic chemical spraying technique. The effects of aging of the starting solution and substrate temperature \\ on the structural, morphological, and electrical properties of the ZnO:F:Zr films have been studied. The resistivity of the films \\ decreases with the aging time of the starting solution until the seventeenth day reaching a minimum of about $1.2 \times 10^{-2} \Omega \mathrm{cm}$ \\ and then increases. Though all the samples are of polycrystalline hexagonal wurtzite type and grow preferentially with (002) plane \\ parallel to the substrate, their morphology depends strongly on the aging time of the reaction solution. The optical transmittance \\ of all the films remained around $80 \%$ in the visible spectral range. These highly transparent, low resistive thin films are expected to \\ be highly useful as transparent electrodes in the fabrication of thin film solar cells.
}

\section{Introduction}

The demand of low-cost and high-performance optoelectronic devices leads to the development of more efficient transparent conductive oxide (TCO) thin films. Among the popular TCOs, the last decade has seen the emergence of zinc oxide $[\mathrm{ZnO}]$ as one of the most important materials for manufacturing transparent electrodes utilized in the fabrication of amorphous silicon-based solar cells. Apart from their high optical transparency, the $\mathrm{ZnO}$ thin films are highly stable in the hydrogen-plasma environment commonly used for the fabrication of silicon-based p-i-n structures [1].

$\mathrm{ZnO}$ thin films have been deposited by a wide variety of techniques, like evaporation [2], sputtering [3], chemical vapor deposition $[4,5]$, sol-gel $[6,7]$, and chemical spray $[8$, 9], among others. Among those, the chemical spray technique has been successfully used for the deposition of conductive and transparent $\mathrm{ZnO}$ thin films. Keeping in mind the high optical transparency as one of the basic requirements, incorporation of several dopants has been tried to reduce the resistivity of $\mathrm{ZnO}$ films. On the other hand, like all the chemical deposition techniques, chemical spray technique involves several parameters or deposition conditions which control the physical properties of the fabricated thin films. However, a complete knowledge of the effect of deposition conditions on the physical characteristics of $\mathrm{ZnO}$ thin films is far from being reached.

The spray pyrolysis technique is based on the pyrolytic decomposition of small droplets of a zinc-containing solution onto a heated substrate, under atmospheric conditions [10]. The low cost of the equipment, the simple atomization process, and both temperature and solution flow control are the main advantages of this technique. Although it is important to highlight that, a deposition process at ambient atmosphere is a strong limiting factor in some applications requiring a clean atmosphere [11].

For electrode manufacturing, oriented $\mathrm{ZnO}$ films doped with adequate impurities are required for their low resistivity in the order of $10^{-3} \Omega \mathrm{cm}$. In this respect, stable $\mathrm{ZnO}$ thin films of low resistivity [12] could be fabricated utilizing group 
III elements like aluminium [Al] and gallium [Ga] as dopants. However, frequently an additional postdeposition annealing either in vacuum $[13,14]$ or under molecular hydrogen atmosphere [15] was required to achieve their low resistivity. On the other hand, incorporation of some other elements with higher valencies into the $\mathrm{ZnO}$ lattice is viewed as another chance in the quest of obtaining low-resistivity thin films $[16,17]$. As a matter of fact, recently Paul et al. [18] have deposited zirconium-doped $\mathrm{ZnO}$ thin films [ $\mathrm{ZnO}: \mathrm{Zr}$ ] by the sol-gel technique, finding that the doping concentration affects both their surface texture and resistivity. $\mathrm{ZnO}$ films with resistivity as low as $7.2 \times 10^{-2} \Omega \mathrm{cm}$ could be deposited with an optimum zirconium $[\mathrm{Zr}]$ concentration of 1.5 at.\%. It is worth to mention that to achieve low resistivity those films were heat-treated several times either in air or in vacuum between 50 and $550^{\circ} \mathrm{C}$. The reduction of resistivity of the $\mathrm{ZnO}: \mathrm{Zr}$ films was considered to be due to the substitution of divalent $\mathrm{Zn}$ atoms from the lattice sites of $\mathrm{ZnO}$ by tetravalent $\mathrm{Zr}$ atoms. However, to the best of our knowledge, there is no report on a detailed study of the effect of $\mathrm{Zr}$ on the electrical properties of chemically sprayed $\mathrm{ZnO}$ thin films applicable as TCOs.

On the other hand, anionic impurities like fluorine $[\mathrm{F}]$ have also been tried to reduce the resistivity of semiconductor oxide thin solid films [19], through the substitution of oxygen atoms of their lattice. It has been observed that the incorporation of $\mathrm{F}$ in the oxide matrix depends strongly on the aging time of precursor solution containing F. Low resistive $\mathrm{ZnO}: \mathrm{F}$ films could be obtained by increasing the aging time of the precursor solution. Taking into account that the incorporation of both anionic and cationic impurities helps to reduce the resistivity of several metal oxide systems [20], we tried to incorporate both $\mathrm{F}$ and $\mathrm{Zr}$ into the $\mathrm{ZnO}$ lattice to obtain its thin films of lower resistivity.

An ultrasonic spray pyrolysis technique was employed to prepare zinc oxide co-doped with fluorine and zirconium (ZnO:F:Zr) thin solid films on glass substrates at different aging times of the precursor solution and at different substrate temperatures to study the effects of these two parameters on their morphological, optical, and electrical properties.

\section{Experimental Details}

2.1. Fabrication of ZnO:F:Zr Thin Solid Films. Ultrasonic spray pyrolysis (USP) is a versatile technique capable of producing nanostructured powder and thin film samples. The particle/grain size in these samples can be straightforwardly controlled by varying the concentration of the source solution and the atomization parameters. The deposition system used in this work includes a variable frequency piezoelectric transducer, which was set to $1.2 \mathrm{MHz}$ and operated at $120 \mathrm{~W}$ ultrasonic powers. In the ultrasonic spray pyrolysis system, a geyser is formed in the liquid surface by the action of a beam of ultrasonic vibrations which is directed to a liquid-gas interface. This geyser is followed by the generation of a spray formed by microscopic droplets. A carrier gas transports and directs the spray toward the surface of a hot substrate where the film formation is produced. The experimental setup used for the fabrication of $\mathrm{ZnO}: \mathrm{F}: \mathrm{Zr}$ films in this work

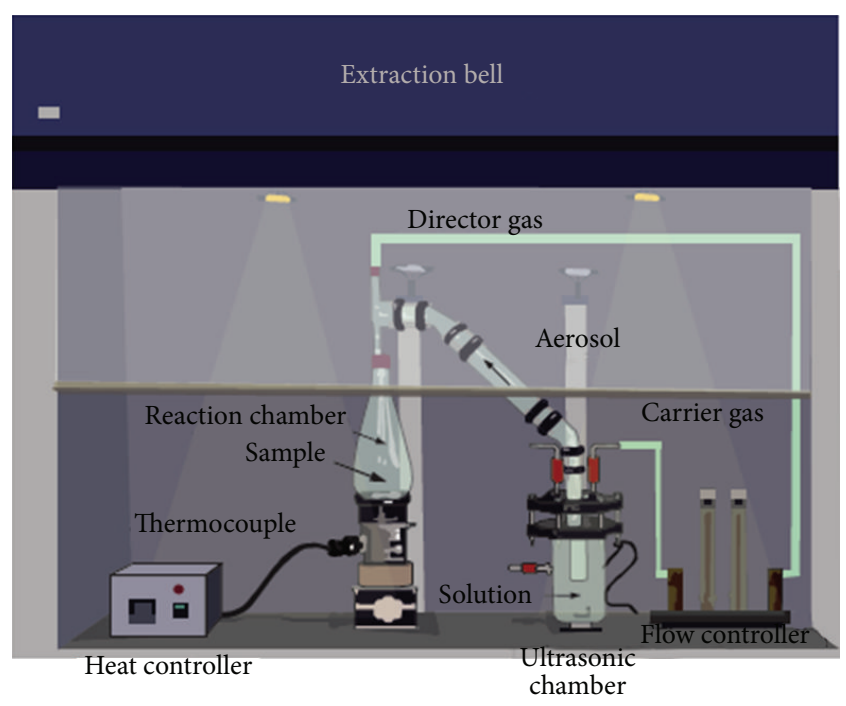

FIGURE 1: Schematic diagram of the experimental setup used for the preparation of $\mathrm{ZnO}: \mathrm{F}: \mathrm{Zr}$ thin films.

is schematically presented in Figure 1. The precursor solution used for the film deposition was prepared by dissolving zinc (II) pentanedionate $\left[\mathrm{Zn}\left(\mathrm{C}_{5} \mathrm{H}_{7} \mathrm{O}_{2}\right)_{2} \cdot \mathrm{H}_{2} \mathrm{O}\right]$ in acetic acid $\left[\mathrm{CH}_{3} \mathrm{CO}_{2} \mathrm{H}\right]$ and methanol $\left[\mathrm{CH}_{3} \mathrm{OH}\right]$ mixture $(12.5: 487.5$, $\mathrm{v} / \mathrm{v}$ ) under magnetic stirring to obtain a $0.2 \mathrm{M}$ concentration of $\mathrm{Zn}$ in it. After the complete dissolution of zinc precursor, measured amounts of zirconium (IV) acetylacetonate $\left[\mathrm{Zr}\left(\mathrm{O}_{2} \mathrm{C}_{5} \mathrm{H}_{7}\right)_{4}\right]$ and ammonium fluoride $\left[\mathrm{NH}_{4} \mathrm{~F}\right]$ were added to the mixture keeping $\mathrm{Zr}$ and $\mathrm{F}$ atom\% (nominal) 3.0 and $30.0 \%$ of $\mathrm{Zn}$ atoms. The $\mathrm{pH}$ of the final precursor solution was adjusted to 4 by adding excess acetic acid. While the concentrations of the dopants in the precursor solution were fixed taking into account the optimum dopant concentrations of anionic and cationic dopants reported in the literature, the addition of excess acetic acid or the final $\mathrm{pH}$ value of the precursor solution was to avoid an early precipitation of zinc hydroxide from it. Prior to deposition the starting solution was kept in dark at room temperature $\left(23^{\circ} \mathrm{C}\right)$ in order to obtain the named aged solution. For ultrasonic spray, aliquots from the precursor solution were collected at different aging times.

The thin films were deposited on glass substrates (alkalifree borosilicate) with an area of $2.5 \times 2.5 \mathrm{~cm}^{2}$, and the substrates have a thickness of $0.5 \mathrm{~cm}$. Prior to film deposition, all the glass substrates were cleaned using the procedure as follows: (i) sonication for five minutes in detergent free of sodium, followed by (ii) sonication for five minutes in trichloroethylene $\left[\mathrm{C}_{2} \mathrm{HCl}_{3}\right]$ for degreasing the substrates, followed by (iii) sonication in methyl alcohol $\left[\mathrm{CH}_{3} \mathrm{OH}\right]$ and (iiii) sonication in acetone $\left[\mathrm{CH}_{3} \mathrm{COCH}_{3}\right]$, and finally (v) the substrates are dried by a jet of pure and dry nitrogen $\left[\mathrm{N}_{2}\right]$. Then the substrates were placed on a fused tin bath of the deposition system. The substrate temperature $\left(T_{s}\right)$ was measured by putting a chromel-alumel thermocouple placed below. The deposition system or the reactor was covered with a stainless steel metal jacket during the pyrolysis process. The 
substrate temperature $\left(T_{s}\right)$ was varied from 450 to $500^{\circ} \mathrm{C}$ in $25^{\circ} \mathrm{C}$ steps, within an accuracy of $\pm 1^{\circ} \mathrm{C}$. Pure $\mathrm{N}_{2}$ was used both as the solution carrier and precursor directing gas, maintaining its flow rates at 3.5 and $0.5 \mathrm{~L} / \mathrm{min}$, respectively. High resistive films were obtained when the depositions were performed at lower and higher temperatures of the substrate out of this range $\left(450^{\circ} \mathrm{C} \geq T_{s} \geq 500^{\circ} \mathrm{C}\right)$. The deposition time was controlled in order to get thickness values around $550 \mathrm{~nm}$.

2.2. Characterization of ZnO:F:Zr Thin Solid Films. The crystallinity and microstructure of the deposited films were determined by X-ray diffraction (XRD) technique by recording the XRD spectra of the samples in $\theta-2 \theta$ scan mode in the range of 30 to $80^{\circ}$, utilizing the $\mathrm{Cu} K \alpha_{1}(\lambda=0.15405 \mathrm{~nm})$ radiation. The thickness and the roughness of the films were obtained using a profilometer on the step formed right after deposition. The morphology of the films was studied by scanning electron microscopy (SEM). Before observations were made, the samples were coated with a very thin metallic deposit in order to improve the resolution of the micrographs, which in turn were directly recorded in a PC system connected to the microscope. Optical transmittance spectra of the films in the 200 to $1000 \mathrm{~nm}$ spectral range were obtained in a spectrophotometer, using a cleaned glass substrate as reference. The electrical sheet resistance of all the samples was measured by the conventional four-aligned probe method with the appropriate correction factors; the characterization was carried out in an open-air atmosphere.

\section{Results and Discussions}

3.1. Structural Evaluation of the ZnO:F:Zr Thin Solid Films. Profilometry estimated thickness of the deposited films varied between 530 and $550 \mathrm{~nm}$ with an accuracy of $10 \%$. The surface profile or the roughness of the films was measured by profilometry, and the values were $10 \mathrm{~nm}$ for one day, $13 \mathrm{~nm}$ for nine days, and finally $15 \mathrm{~nm}$ for twenty days. On the other hand, X-ray diffraction patterns of the as-grown $\mathrm{ZnO}: \mathrm{F}: \mathrm{Zr}$ thin films deposited using the precursor solutions aged 1 day, 9 days, and 20 days at $500^{\circ} \mathrm{C}$ of substrate temperature shown in Figure 2. From the XRD patterns it is clear that all the samples are of polycrystalline nature. The XRD peak positions of all the samples fit well to hexagonal wurtzite phase of $\mathrm{ZnO}$ (JCPDS no. 36-1451). No diffraction peak related to zirconium or any compound of zirconium or fluorine was detected. All the samples revealed their preferential growth along the [002] direction, that is, (002) planes grown parallel to the substrate surface. The results indicate that in the studied range of 450$500^{\circ} \mathrm{C}$ the temperature of the substrate $\left(T_{s}\right)$ does not affect significantly the preferential growth of $\mathrm{ZnO}: \mathrm{F}: \mathrm{Zr}$ films on glass substrate. The signal intensities from each of the X-ray diffraction patterns contain information on the preferential or random growth of polycrystalline thin films following the expression [21]

$$
T_{c}(\mathrm{hkl})=\frac{\left[I(\mathrm{hkl}) / I_{r}(\mathrm{hkl})\right]}{1 / N \Sigma\left[I(\mathrm{hkl}) / I_{r}(\mathrm{hkl})\right]},
$$

where $T_{c}(\mathrm{hkl})$ is the corresponding texture coefficient, $I(\mathrm{hkl})$ are the X-ray diffraction intensities of the sample, and $N$ is

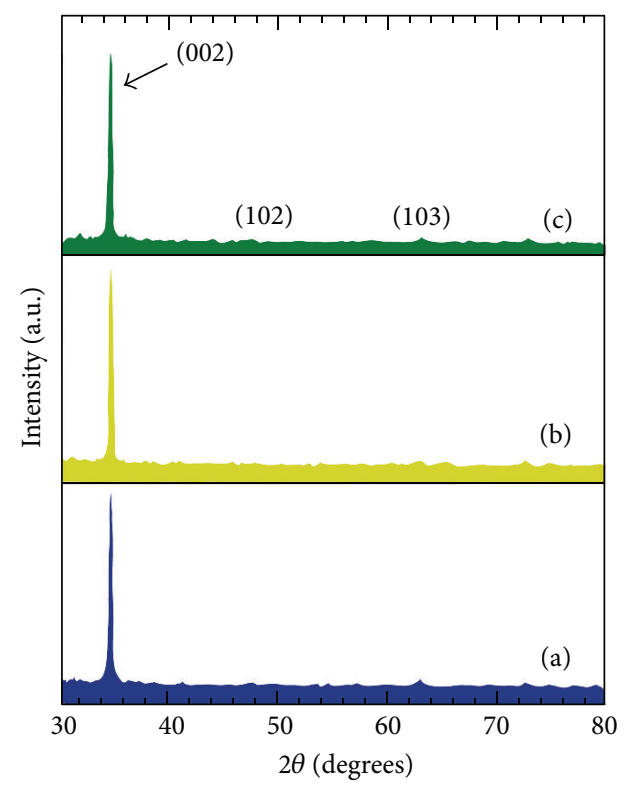

FIgURE 2: X-ray diffraction patterns of ZnO:F:Zr thin films deposited at $T_{s}=500^{\circ} \mathrm{C}$, utilizing the precursor solutions of (a) 1 day, (b) 9 days, and (c) 20 days of aging time.

the number of diffraction peaks considered. $I_{r}(\mathrm{hkl})$ are the intensities of the reference/standard XRD pattern (JCPDS no. 36-1451). Considering the most intense (002) XRD peak, the texture coefficient for all the samples is estimated to be of the order of $0.3( \pm 10 \%)$. The estimated $T_{c}$ values lower than 1 indicate the abundance of crystalline grains oriented along [002] direction in all the samples. The crystallite size was estimated using the (002) diffraction peak from the XRD data in accordance with the Debye-Scherer formula [22]:

$$
D=\frac{0.9 \lambda}{B \cos \theta}
$$

where $D$ is the crystallite size in nanometers, $\lambda$ is the wavelength value of the $\mathrm{Cu} \mathrm{K}_{\alpha 1}$ line, $\theta$ is the Bragg diffraction angle, and $B$ is the FWHM of the diffraction peak measured in radians. An average crystallite size value corresponding to films deposited at every substrate temperature with an accuracy of $10 \%$ is listed in Table 1 . According to these results, the crystallite size of the $\mathrm{ZnO}: \mathrm{F}: \mathrm{Zr}$ thin solid films decreases from 20 to $100 \mathrm{~nm}$ as-grown $\mathrm{ZnO}: \mathrm{F}: \mathrm{Zr}$ thin solid films deposited using the precursor solutions aged 1-20 days at $500^{\circ} \mathrm{C}$ of substrate temperature.

\subsection{Morphology Evaluation of the ZnO:F:Zr Thin Solid Films.} The surface morphology of ZnO:F: Zr, thin solid films deposited from starting solutions aged at one, nine, and twenty days, is shown in Figure 3. From the scanning electron microscopy images (SEM) slight changes are observed when the solution ageing time increases from one to twenty days. A porous surface consisting of definite rounded grains, with an average diameter around $120 \mathrm{~nm}$, and separated by voids appears in the samples deposited from a one-day aged solution, as is shown in Figure 3(a). A uniform and more compact 
TABLE 1: Crystallite size and thickness for the different substrate temperatures.

\begin{tabular}{lccc}
\hline $\begin{array}{l}\text { Time of aging of } \\
\text { the solution (days) }\end{array}$ & $\begin{array}{c}\text { Substrate } \\
\text { temperature } \\
\left({ }^{\circ} \mathrm{C}\right)\end{array}$ & $\begin{array}{c}\text { Crystallite size } \\
(\mathrm{nm}) \pm 10 \%\end{array}$ & $\begin{array}{c}\text { Thickness } \\
(\mathrm{nm})\end{array}$ \\
\hline 1 & 500 & 20.18 & 530 \\
9 & 500 & 47.95 & 535 \\
20 & 500 & 99.55 & 540 \\
\hline
\end{tabular}

surface with uniform grain size $(\sim 90 \mathrm{~nm})$ is observed in the samples deposited from a nine-day aged solution, as can be seen in Figure 3(b). Finally, films deposited from a solution aged for twenty days (Figure 3(c)) with an irregular surface morphology, a higher roughness, and numerous voids, but similar grain size, can be evidenced at naked eye. It is worthy to mention that these characteristics have not been previously reported concerning ultrasonic chemical pyrolysis zirconium and fluorine doping $\mathrm{ZnO}$ thin films.

\subsection{Optical Properties of the ZnO:F:Zr Thin Solid Films.} Figure 4 shows the optical transmission spectra of the $\mathrm{ZnO}: \mathrm{F}: \mathrm{Zr}$ films deposited at $475^{\circ} \mathrm{C}$ using the precursor solutions of different aging times. All the films were uniform and transparent to naked eyes. Optical transmittance of all the samples remained high (80-85\%) in the visible spectral range, irrespective of their deposition temperature of the age of the used aliquot. Though the optical transparency of the films varied a bit with deposition conditions in the ultraviolet spectral range (which is irrelevant for the fabrication of TOC electrode applications), the position of their band edge did not vary significantly. Considering a direct allowed transition in the samples, the optical band gap energy of the samples estimated using the Swanepoel method [23] was close to $3.30 \mathrm{eV}$ for $T_{s}=500^{\circ} \mathrm{C}$ and $3.33 \mathrm{eV}$ for $T_{s}=475^{\circ} \mathrm{C}$ from starting solutions with different aging times.

3.4. Electrical Properties of the ZnO:F:Zr Films. The variation of electrical resistivity of the ZnO:F:Zr thin films with the aging time of precursor solutions is presented in Figure 5 for the samples deposited at different substrate temperatures $\left(T_{s}\right)$. As can be seen from the figure, the samples deposited using the precursor solution aged 1 day manifest highest resistivity $2-0.1 \Omega \mathrm{cm}$. On increasing the age of the precursor solution, the resistivity of the deposited films decreases gradually, reaching a minimum value $\sim 1.2 \times 10^{-2} \Omega \mathrm{cm}$ for the 17-20 days of aliquot age, when they were deposited at $T_{s}=$ $500^{\circ} \mathrm{C}$. However, for the lower value of substrate temperature (e.g., $T_{s}=450^{\circ} \mathrm{C}$ ), the precursor solution had to be aged longer (25-28 days) to obtain the thin films of minimum resistivity (Figure 5). An increase in the resistivity values is observed for the films deposited using longer aging time. The observed variation of film resistivity with the aging time of the precursor solution can be tentatively explained considering the mechanism of incorporation of dopants in them. The $\mathrm{Zr}^{4+}$ ions from the dissolved zirconium (IV) acetylacetonate can replace $\mathrm{Zn}^{2+}$ ions from their lattice sites easily (fast

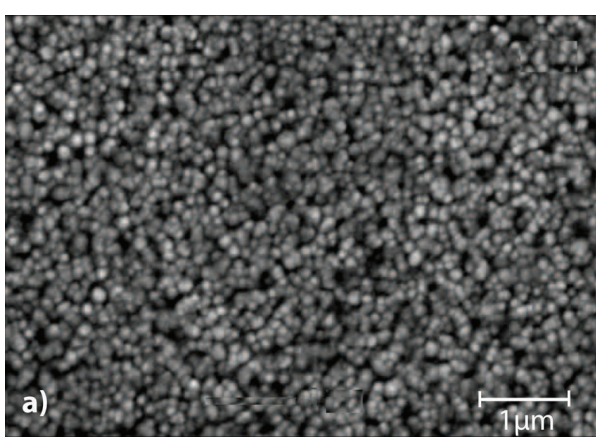

(a)

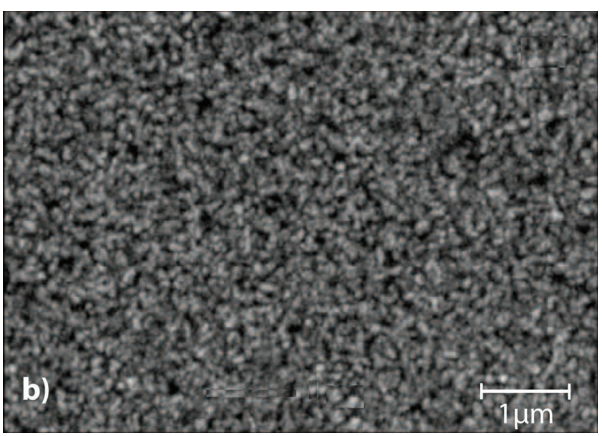

(b)

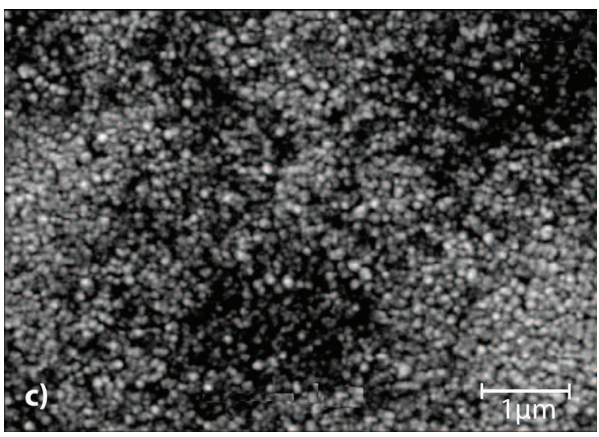

(c)

FIgURE 3: SEM micrographs of ZnO:F:Zr thin films deposited at $T_{s}=$ $500^{\circ} \mathrm{C}$, utilizing the precursor solutions of (a) 1 day, (b) 9 days, and (c) 20 days of aging time.

incorporation) due to their similar ionic radii (88 and 86 pm for $\mathrm{Zn}^{2+}$ and $\mathrm{Zr}^{4+}$, resp.). On the other hand, even with smaller ionic radius (ionic radii of $\mathrm{O}^{2-}$ and $\mathrm{F}^{-}$being 126 and $119 \mathrm{pm}$, resp.), the monovalent $\mathrm{F}^{-}$ions cannot substitute the divalent $\mathrm{O}^{2-}$ ions from the lattice sites of $\mathrm{ZnO}$ very easily due to the strong ionic nature of $\mathrm{Zn}-\mathrm{O}$ bonds. In this way, it is believed that group III ions replace $\mathrm{Zn}^{2+}$, increasing the carrier concentration and hence lowering the resistivity of the $\mathrm{ZnO}$ thin films. An alternative way to reach the same goal is the replacement of oxygen ions $\left(\mathrm{O}^{2-}\right)$ of the $\mathrm{ZnO}$ lattice by a lower valence element, such as fluorine $\left(\mathrm{F}^{-1}\right)$.

The variation of substrate temperature also affects the resistivity of $\mathrm{ZnO}: \mathrm{F}: \mathrm{Zr}$ thin films. In general, the resistivity of the fabricated films decreased with the increase of substrate temperature. However, the required time of precursor 


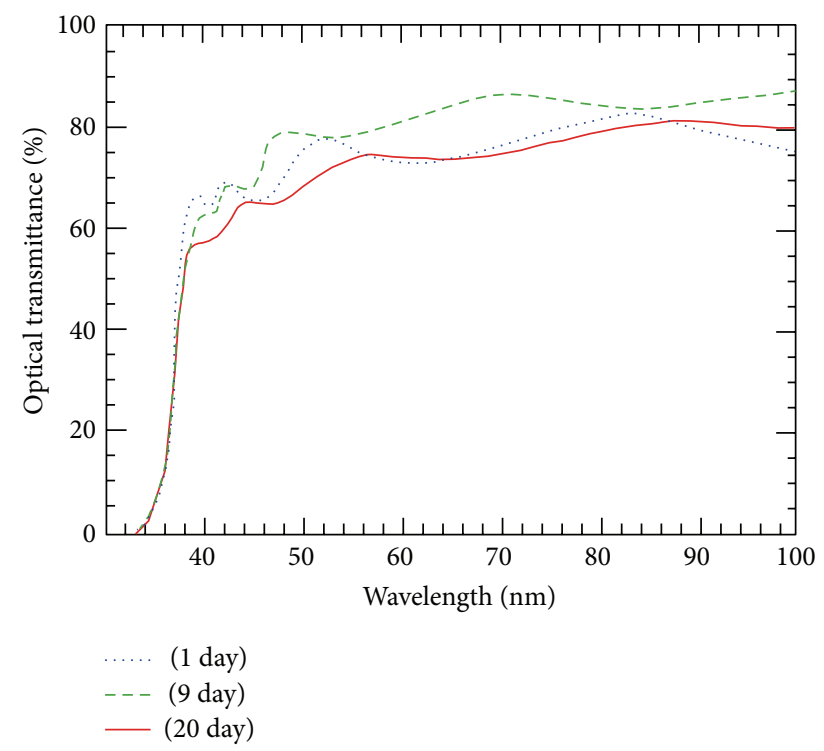

FIgURE 4: Optical transmittance spectra of $\mathrm{ZnO}: \mathrm{F}: \mathrm{Zr}$ thin films deposited at $T_{s}=500^{\circ} \mathrm{C}$ utilizing the precursor solution aged one, nine, and twenty days.

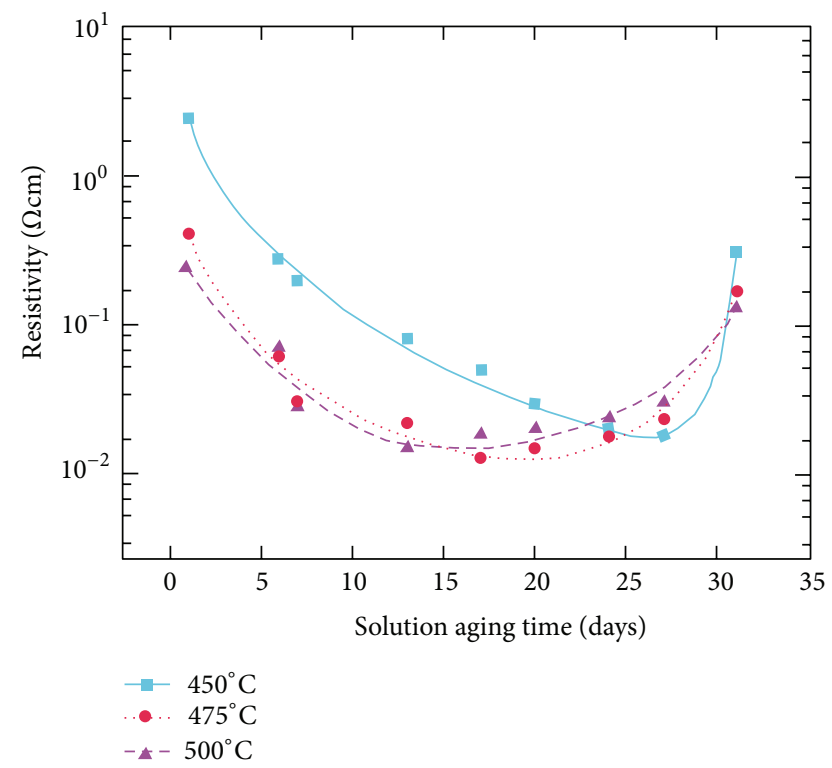

FIGURE 5: Resistivity variation of the $\mathrm{ZnO}: \mathrm{F}: \mathrm{Zr}$ thin films as a function of aging time of the precursor solution.

solution aging to obtain the films of minimum resistivity reduces gradually with the increase of substrate temperature. For example, the optimum aging time for the films grown at 450,475 , and $500^{\circ} \mathrm{C}$ substrate temperatures was 27,20 , and 13 days, respectively. Higher substrate temperature helps to reduce the $\mathrm{Zn}-\mathrm{O}$ bond strength facilitating the substitution of $\mathrm{O}$ atoms by $\mathrm{F}$. As has been mentioned earlier, a further increase of substrate temperature $\left(T_{s}>500^{\circ} \mathrm{C}\right)$ increases the resistivity of the films, which might be due to the escape of volatile $\mathrm{F}$ from the $\mathrm{ZnO}$ lattice.
Absence of XRD peaks associated with any other compound rather than $\mathrm{ZnO}$ in the diffraction patterns of the samples indicates both dopants incorporated into the $\mathrm{ZnO}$ lattice through substitution. It is worth mentioning that the minimum resistivity measured in our $\mathrm{ZnO}: \mathrm{F}: \mathrm{Zr}$ thin films is lower than the reported minimum resistivity of doped or undoped $\mathrm{ZnO}$ thin films fabricated by sol-gel process. Moreover, our USP fabricated ZnO:F:Zr films required no postdeposition heat treatment as in the case of several reported works.

\section{Conclusions}

In summary, we could fabricate smooth, pinhole-free, considerably low resistive $\mathrm{ZnO}: \mathrm{F}: \mathrm{Zr}$ thin films with high transmittance by ultrasonic spray pyrolysis technique. While the lowest resistivity of our films was $\sim 1.2 \times 10^{-2} \Omega \mathrm{cm}$, their optical transparency was as high as $80 \%$. Both these values are adequate for utilizing these thin films as TCO electrodes in solar cell. The resistivity of the films depends strongly on the aging time of precursor solution, as well as the temperature of substrates during their deposition. In the $450-500^{\circ} \mathrm{C}$ range of substrate temperature, $\mathrm{ZnO}: \mathrm{F}: \mathrm{Zr}$ thin films of lowest resistivity could be obtained for the aging time of precursor solution as short as 13 days. $T_{s}=500^{\circ} \mathrm{C}$ is seen to be optimum for obtaining lowest resistive $\mathrm{ZnO}: \mathrm{F}: \mathrm{Zr}$ thin solid films with shortest aging time of precursor solution. A higher substrate temperature inhibits the incorporation of $\mathrm{F}$ in $\mathrm{ZnO}$ films. The minimum resistivity value of our $\mathrm{ZnO}: \mathrm{F}: \mathrm{Zr}$ thin solid films is lower than the reported minimum resistivity values of $\mathrm{ZnO}$ thin films (either doped or undoped) fabricated by sol-gel process. As the films fabricated in this work need no postdeposition thermal treatment, they are expected to be highly attractive for transparent electrodes in solar cell fabrication.

\section{Acknowledgment}

L. Castañeda gratefully acknowledges the financial support from the Escuela Superior de Ingeniería Mecánica y Eléctrica Unidad Ticomán, Instituto Politécnico Nacional, through Project no. 20130759.

\section{References}

[1] P. S. Patil, "Versatility of chemical spray pyrolysis technique," Materials Chemistry and Physics, vol. 59, no. 3, p. 185, 1999.

[2] S. A. Aly, N. Z. El Sayed, and M. A. Kaid, "Effect of annealing on the optical properties of thermally evaporated $\mathrm{ZnO}$ films," Vacuum, vol. 61, no. 1, pp. 1-7, 2001.

[3] T. Minani, T. Yamamoto, and T. Miyata, "Highly transparent and conductive rare earth-doped $\mathrm{ZnO}$ thin films prepared by magnetron sputtering," Thin Solid Films, vol. 366, pp. 63-68, 2000.

[4] K. Kobayashi, T. Matsubara, S. Matsushima, S. Shirakata, S. Isomura, and G. Okada, "Preparation of c-axis oriented $\mathrm{ZnO}$ films by low-pressure organometallic chemical vapor deposition," Thin Solid Films, vol. 266, no. 2, pp. 106-109, 1995.

[5] T. Kawaharamura and S. Fujita, "An approach for single crystalline zinc oxide thin films with fine channel mist chemical 
vapor deposition method," Physica Status Solidi C, vol. 5, no. 9, pp. 3138-3140, 2008.

[6] Y. Natsume and H. Sakata, "Zinc oxide films prepared by sol-gel spin-coating," Thin Solid Films, vol. 372, no. 1, pp. 30-36, 2000.

[7] L. Castañeda, M. Avendaño-Alejo, H. Gomez, M. de la L. Olvera, and A. Maldonado, "Physical characterization of ruthenium-doped zinc oxide thin solid films deposited by the sol-gel technique: gas-sensing performance in a propane atmosphere," Sensor Letters, vol. 11, no. 2, pp. 286-293, 2013.

[8] M. Krunks and E. Mellikov, "Zinc oxide thin films by the spray pyrolysis method," Thin Solid Films, vol. 270, no. 1-2, pp. 33-36, 1995.

[9] L. Castañeda, A. García-Valenzuela, E. P. Zironi, J. CañetasOrtega, M. Terrones, and A. Maldonado, "Formation of indium-doped zinc oxide thin films using chemical spray techniques: the importance of acetic acid content in the aerosol solution and the substrate temperature for enhancing electrical transport," Thin Solid Films, vol. 503, no. 1-2, pp. 212-218, 2006.

[10] J. B. Mooney and S. B. Radding, "Spray pyrolysis processing," Annual Review of Materials Science, vol. 12, pp. 81-101, 1982.

[11] L. Castañeda, A. Maldonado, J. C. Cheang-Wong, J. RodriguezBaez, M. López-Fuentes, and M. de la L. Olvera, "Chemical spray pyrolysis deposited fluorine-doped zinc oxide thin films: effect of acetic acid content in the starting solution on the physical properties," Materials Science in Semiconductor Processing, vol. 15, pp. 232-239, 2012.

[12] M. de la L. Olvera, A. Maldonado, and R. Asomoza, " $\mathrm{ZnO}: \mathrm{F}$ thin films deposited by chemical spray: effect of the fluorine concentration in the starting solution," Solar Energy Materials and Solar Cells, vol. 73, no. 4, pp. 425-433, 2002.

[13] H. Mondragón-Suárez, A. Maldonado, M. de la L. Olvera et al., "ZnO:Al thin films obtained by chemical spray: effect of the Al concentration," Applied Surface Science, vol. 193, no. 1-4, pp. 5259, 2002.

[14] S. Major and K. L. Chopra, "Indium-doped zinc oxide films as transparent electrodes for solar cells," Solar Energy Materials, vol. 17, pp. 319-327, 1988.

[15] P. Nunes, B. Fernandes, E. Fortunato, P. Vilarinho, and R. Martins, "Performances presented by zinc oxide thin films deposited by spray pyrolysis," Thin Solid Films, vol. 337, no. 12, pp. 176-179, 1999.

[16] A. Tiburcio-Silver, A. Sánchez-Juárez, and A. Avila-García, "Properties of gallium-doped $\mathrm{ZnO}$ deposited onto glass by spray pyrolysis," Solar Energy Materials and Solar Cells, vol. 55, no. 1-2, pp. 3-10, 1998.

[17] B. J. Lokhande, P. S. Patil, and M. D. Uplane, "Studies on structural, optical and electrical properties of boron doped zinc oxide films prepared by spray pyrolysis technique," Physica $B$, vol. 302-303, pp. 59-63, 2001.

[18] G. K. Paul, S. Bandyopadhyay, S.-K. Sen, and S. Sen, "Structural, optical and electrical studies on sol-gel deposited $\mathrm{Zr}$ doped $\mathrm{ZnO}$ films," Materials Chemistry and Physics, vol. 79, pp. 71-75, 2003.

[19] A. Guillén-Santiago, M. de la L. Olvera, A. Maldonado, R. Asomoza, and D. R. Acosta, "Electrical, structural and morphological properties of chemically sprayed F-doped $\mathrm{ZnO}$ films: effect of the ageing-time of the starting solution, solvent and substrate temperature," Physica Status Solidi A, vol. 201, no. 5, pp. 952-959, 2004.

[20] O. G. Morales-Saavedra, L. Castañeda, J. G. Bañuelos, and R. Ortega-Martínez, "Morphological, optical, and nonlinear optical properties of fluorine-indium-doped zinc oxide thin films," Laser Physics, vol. 18, pp. 283-291, 2008.
[21] C. Barrette and T. B. Massalaski, Structure of Metals, McGrawHill, New York, NY, USA, 1966.

[22] B. E. Warren, X-Ray Diffraction, Dover, New York, NY, USA, 1990.

[23] R. Swanepoel, "Determination of the thickness and optical constants of amorphous silicon," Journal of Physics E, vol. 16, no. 12, pp. 1214-1222, 1983. 

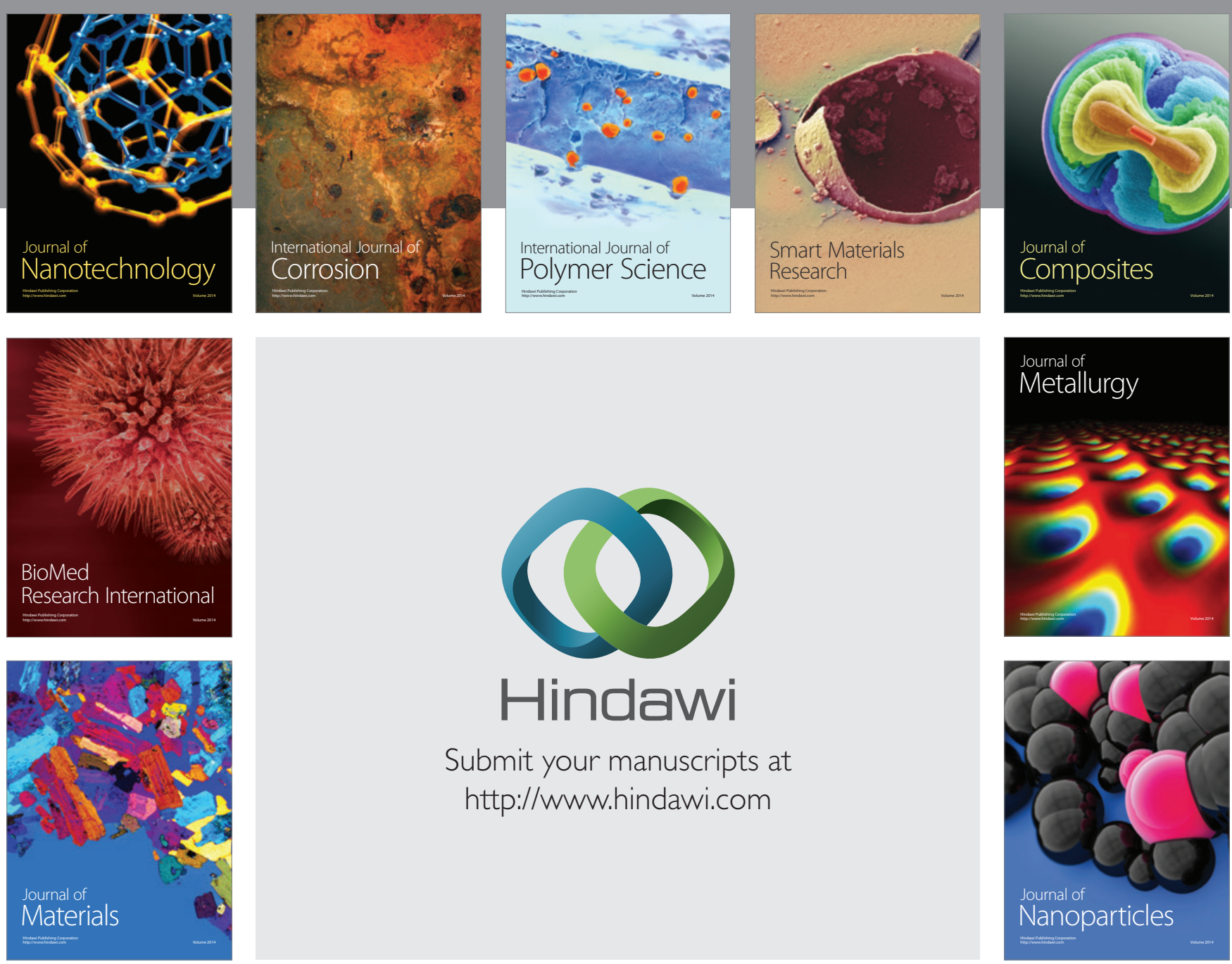

Submit your manuscripts at http://www.hindawi.com
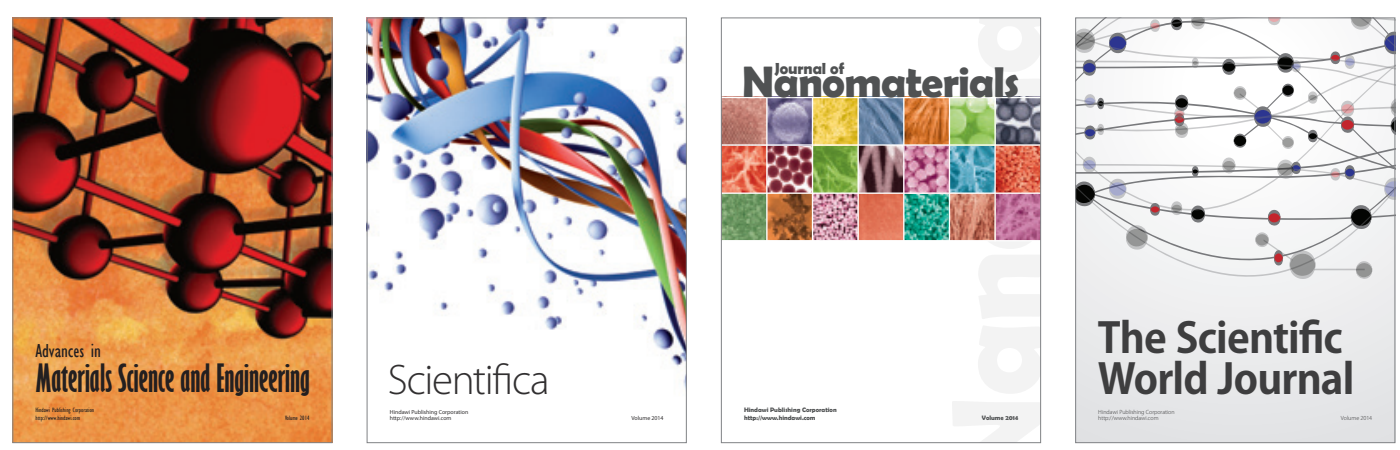

\section{The Scientific World Journal}
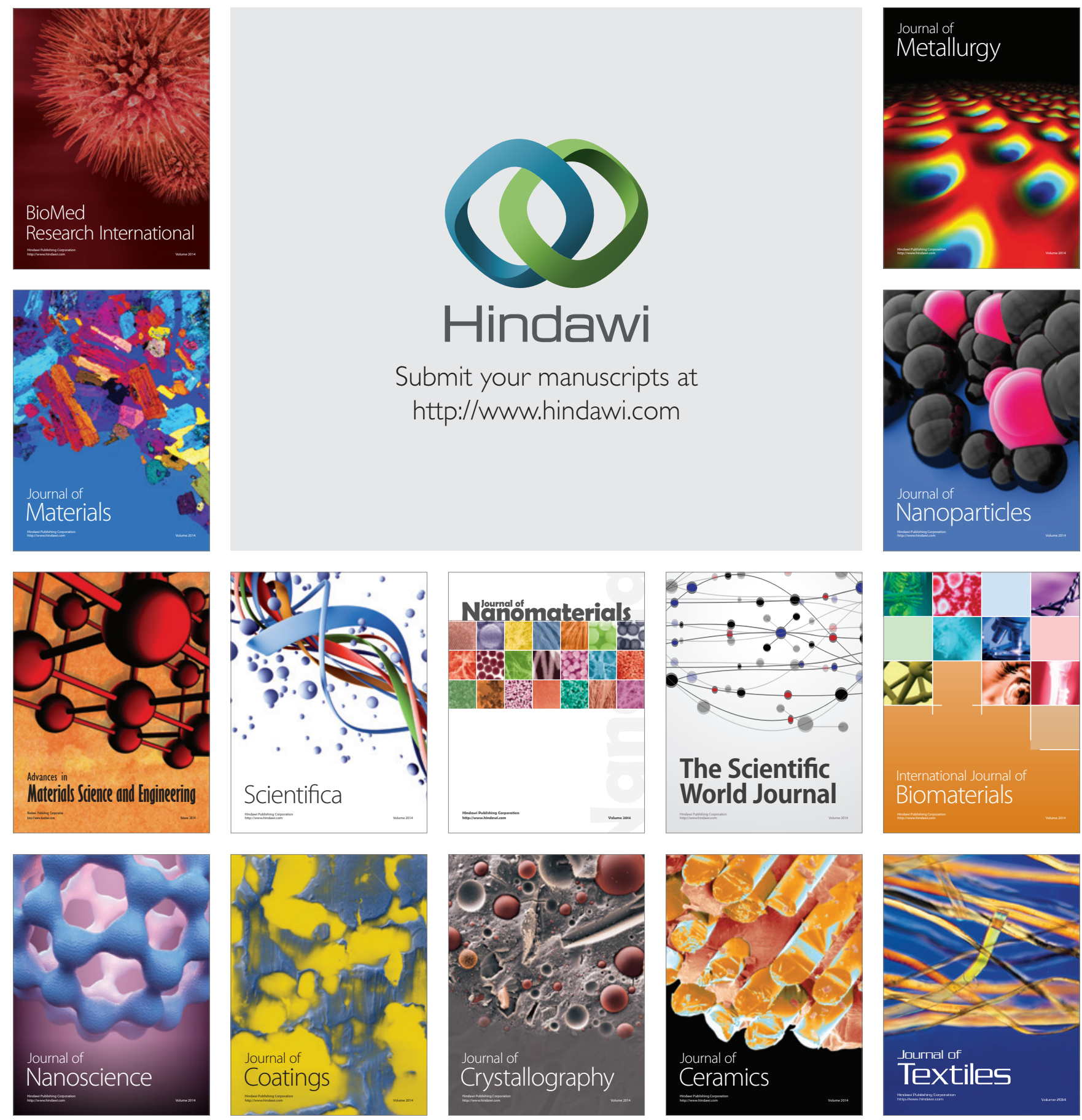